\title{
Casos clínicos sobre trasplante renal
}

\author{
Dolores Andreu Périz, Miguel Ángel Hidalgo Blanco, Carmen Moreno Arroyo
}

Departamento de Enfermería Fundamental y Médico Quirúrgica. Facultad de Medicina y Ciencias de la Salud. Universitat de Barcelona. España

Puesto que el interés de un caso clínico radica en que presente una situación especial, se ha de valorar al publicarlo qué tipo de novedad ofrece. Su interés puede radicar, entre otros, en presentar una patología poco frecuente, en la respuesta anómala de un paciente ante un tratamiento o en la descripción de una intervención terapéutica innovadora. El trasplante renal es hoy día la opción deseable para las personas que padecen enfermedad renal terminal y desde el punto de vista quirúrgico puede considerarse de muy poco riesgo.

Desde que se documentó el primer trasplante renal en $1933^{1}$, los avances han sido muy importantes. EI mejor conocimiento de la genética y el desarrollo de fármacos inmunosupresores han propiciado que las personas trasplantadas alcancen supervivencias de varias décadas con muy buena calidad de vida. Un mejor diagnóstico de la Enfermedad Renal y la mejora de las técnicas dialíticas, más la posibilidad de retrasplante a un paciente han generado largas lista de espera y la obtención de un órganos continua siendo muy inferior a la demanda².

Se han abierto numerosas líneas de investigación buscado soluciones para mejorar el tratamiento y paliar la escasez de donantes. El complejo engranaje que precisa el binomio donante-receptor es imprescindible para garantizar la eficiencia del tratamiento. Estas consideraciones justifican que haya situaciones muy específicas cuyo curso es interesante para los profesionales.

\begin{tabular}{|c|}
\hline Correspondencia: \\
Dolores Andreu Périz \\
Departamento de Enfermería Fundamental y Médico Quirúrgica \\
Campus de Bellvitge. C/ Feixa Llarga s/n. \\
08907 L'Hospitalet de Llobregat. Barcelona \\
E-mail: lolaandreu@ub.edu \\
\hline
\end{tabular}

Frecuentemente se publican casos clínicos sobre trasplante y aunque revistas, tanto generalistas como especializadas no admiten casos clínicos, otras los aceptan. En el campo de la Nefrología destacarían CJASN, American Journal of Kydney Disease, JANS y Nefrología. También en esta especialidad hay alguna dedicada a publicar solamente casos clínicos como Clinical and Experimental Nephrology. Case Reports ${ }^{3}$.

A continuación, de los numerosos casos publicados sobre pacientes trasplantados se han seleccionado algunos que recogen infecciones poco frecuentes, por lo que su diagnóstico es difícil, circunstancia que también ocurre cuando las manifestaciones clínicas son muy graves, pero atribuibles a causas muy diversas. En otros se presentan complicaciones a consecuencia del tratamiento o la ayuda de la robótica en la técnica quirúrgica y por último un trasplante excepcional con la descripción del Plan de Cuidados.

\section{Weerakkody RM, Palangasinghe DR, Wijewic- krama ES. Dengue fever in a kidney trans- plant recipient with complicated clinical cour- se: a case report J Med Case Rep. 2018 Sep 1;12(1):260. doi: 10.1186/s13256-018-1790-0.}

El dengue es una enfermedad infecciosa muy común en el trópico que está causada por un virus del genero flavivirus que se transmite por mosquitos. El cuadro clínico se caracteriza por fiebre de más de $38{ }^{\circ} \mathrm{C}$, cefaleas, dolor retroocular, artralgias, mialgias, inflamación de los ganglios linfáticos y petequias que suelen aparecer en las extremidades inferiores y el tórax de los pacientes, desde donde se extienden para abarcar la mayor parte del cuerpo. En casos graves puede producirse un colapso circulatorio y afectar a varios órganos como el riñón. Los pacientes con dengue transmiten la infección únicamente a través de mosquitos 0 
productos derivados de la sangre por un periodo corto de tiempo, por eso, es raro que existan epidemias de dengue fuera del área geográfica del vector.

Este caso describe el curso clínico de una mujer de 59 años con un trasplante estable y en tratamiento con antivirales por una hepatitis B. La paciente vivía en Sri Lanka, país en el que es frecuente la hepatitis $B$ pero muy raro el dengue. Una sobreinfección por dengue se manifestó en ella con gran morbilidad y con una sintomatología inespecífica que hizo muy difícil el diagnóstico; en poco tiempo la paciente presentó una insuficiencia renal aguda que necesitó del apoyo de diálisis. Entre las complicaciones destacaron un sangrado gastrointestinal, por lo que necesitó ser transfundida, pancitopenia, y trombocitopenia de la que tardó meses en recuperarse. Finalmente, la paciente superó la infección sin secuelas destacables, recuperando la función renal.

Los autores alertan sobre la dificultad del diagnóstico de dengue en personas trasplantadas, de sus complicaciones y de la lentitud de la recuperación.

Una reflexión ante este caso es que las personas trasplantadas que viajan a regiones donde el dengue es endémico, deben tener muy en cuenta que tienen una gran indefensión frente a estas y otras infecciones propias de estas zonas, no solo porque el tratamiento inmunosupresor a que están sometidos las hace particularmente lábiles, también por que no conocen bien los mecanismos de prevención y por qué en ellos se puede manifestar de una forma diferente, siendo muy difícil diagnosticarla y se puede confundir con otra más frecuente en su situación de trasplantados.

\section{Yang H, Wang W, Hu X, Zhang X, Liu L. Sirolimus -induced severe small bowel angioedema: A case report. Medicine (Baltimore). 2018 Aug;97(34): e12029. doi: 10.1097/MD.0000000000012029.}

El angioedema intestinal asociado a drogas es una entidad poco frecuente que cursa con episodios recurrentes de dolor, distensión abdominal y diarrea acuosa, con recuperación completa en dos o tres días. El que este cuadro se asocie a fármacos utilizados con frecuencia aconseja incluirla en el diagnóstico diferencial del dolor abdominal recurrente. El interés de este caso radica en el hecho de que el angioedema se asocia a drogas como el enalapril pero no se relaciona el angioedema del intestino delgado con la administración de sirolimus.

A una mujer de 38 años, sin antecedentes de enfermedades gastrointestinales 0 alergias a medicamentos, se le practicó un trasplante de donante cadáver sin complicaciones. El régimen inmunosupresor de la paciente incluía timoglobulina para la terapia de inmunosupresión de inducción y tacrolimus, sirolimus y glucocorticoides para el tratamiento de mantenimiento. Al día de la intervención la paciente presentó dolor gástrico generalizado, empeorando los síntomas en los siguientes días, con dolor cólico, vómitos y diarrea.

Inicialmente, se consideró el cuadro como un efecto secundario de los corticoides por lo que se redujo la dosis. Se mantuvo a la paciente con sonda nasogástrica, ayuno y omeprazol. La tomografía computarizada del abdomen y la pelvis reveló una gran cantidad de líquido intraperitoneal libre adyacente a la cápsula hepática y engrosamiento difuso de la pared del intestino delgado en la mitad del abdomen. Se practicó una laparotomía exploradora que mostró un edema de intestino delgado que se localizó a $50 \mathrm{~cm}$ distal del ligamento de Treitz sin íleo.

Ante la sospecha de que estas manifestaciones estuvieran provocadas por el sirolimus se cambió el régimen inmunosupresor y el sirolimus se sustituyó por micofenolato. Los síntomas desaparecieron en las siguientes 48 horas y la tomografía mostró la resolución completa de la inflamación de la pared del intestino.

Tras una revisión de la literatura los autores sugieren que el sirolimus interfiere con la vía de la bradiquinina, que es un potente mediador de la inflamación y aunque este es el primer caso descrito de angiodema intestinal asociado a sirolimus, se ha de ser consciente de que muchos fármacos inducen un angiodema que puede tener graves consecuencias.

\section{Chang CC, Lin TM, Chan CP, Pan WL. Nonsurgical periodontal treatment and prosthetic rehabilita- tion of a renal transplant patient with gingival enlargement: a case report with 2-year follow-up. BCM Oral Health. 2018 Aug 20;18(1):140. doi: 10.1186/s12903-018-0607-2.}

Los efectos adversos del tratamiento inmunosupresor, especialmente de la ciclosporina y el micofenola- 
to, se pueden manifestar en la cavidad oral e incluyen infecciones oportunistas, siendo la lesión bucal más prevalente la hiperplasia gingival. Histológicamente, esta entidad está constituida por la proliferación de fibroblastos, depósitos de matriz extracelular amorfa e infiltrado inflamatorio. El tejido excesivo, además del compromiso estético, dificulta la higiene bucal, provoca periodontitis y movilidad de los dientes que pueden llegar a caer. En muchas ocasiones, es preciso recurrir a la cirugía para resecar el exceso de tejido.

Este caso plantea la situación de una mujer de 51 años, portadora de un injerto renal con buen funcionamiento desde hacía 16 años, Presentaba un estado de la cavidad bucal muy preocupante debido a una gran hiperplasia gingival que sangraba, movilidad de algunos dientes y dificultad para masticar. Su régimen inmunosupresor incluía ciclosporina, prednisolona y micofenolato mofetil. La higiene bucal era muy deficiente puesto que rara vez se cepillaba los dientes o usaba hilo dental porque le sangraban las encías.

Inicialmente se planteó una cirugía periodontal con extracción del tejido, pero ante el rechazo de la paciente se optó por un tratamiento conservador que incluyó curetaje de las encías y extracción de un molar. Se prescribieron antibióticos profilácticos antes de cada intervención y se le proporcionaron prótesis parciales extraíbles. Se instruyó a la paciente para que realizara una mayor higiene oral con cepillado de raíz y enjuagues con cloexhidrina. Aunque la movilidad dental disminuyó después de varias visitas, la alineación incorrecta de los dientes provocaba un desajuste oclusal que se corrigió modificando, con un tallado, las superficies de contacto de los dientes.

Tras seis meses de tratamiento, la hiperplasia había disminuido considerablemente, tenía una buena masticación y la higiene oral era satisfactoria, por lo que se consideró finalizado el tratamiento de choque y se aconsejó a la paciente visitas regulares al periodontista.

Los autores concluyen que es posible, con el diagnóstico apropiado y con la cooperación del paciente, que se pueden resolver graves problemas de la cavidad bucal de manera conservadora, sin cirugía invasiva, lograr un tejido periodontal estable y restaurar la función de masticación.

No obstante, aunque este caso se haya resulto de manera satisfactoria y como sus autores destacan es imprescindible alertar a las personas que reciben un trasplante sobre la necesidad de visitar regularmente al dentista y practicar una higiene dental rigurosa para prever los problemas de la cavidad oral.

\section{Vignolini G, Sessa F, Greco I, Pili A, Giancane S, Sebastianelli A, Siena G, Gacci M, Li Marzi V, Campi R, Serni S. Robotic Kidney Transplan- tation from a Brain-Dead Deceased Donor in a Patient with Autosomal Dominant Polycystic Kidney Disease: First Case Report.J Endourol Case Rep. 2018 Aug 1;4(1):124-8. doi: 10.1089/ cren.2018.0050. eCollection 2018.}

La poliquistosis renal es una causa frecuente de insuficiencia renal terminal que puede plantear desafíos técnicos para realizar un trasplante de riñón. A pesar de que aún existe controversia con respecto a las indicaciones y el momento de una nefrectomía renal nativa, la evidencia reciente sugiere que en pacientes asintomáticos con poliquistosis, especialmente con diuresis residual, si hay espacio suficiente en la cavidad abdominal, la nefrectomía antes o en el momento de trasplante no debe realizarse pues puede aumentar el riesgo de problemas en el postoperatorio.

Recientemente, se ha informado de excelentes resultados en trasplantes renales ayudados por el robot Vinci Xi Robot ${ }^{\circledR}$ que ha reducido la morbilidad quirúrgica. La mayoría de intervenciones de este tipo se han realizado en trasplantes con donante vivo.

Da Vinci, es un sistema robotizado desarrollo por Intuitive Surgical que consta de dos módulos: brazos y terminal de control. Cuatro brazos robóticos dos de los cuales llevan cámaras de alta resolución que se introducen en orificios de apenas unos milímetros dan al cirujano una visión 3D de la zona a tratar. Los brazos permiten manipular el entorno gracias a útiles intercambiables, similares a los empleados en operaciones de laparoscopia El robot se emplea principalmente para operaciones de cáncer de próstata aunque su uso se puede extender a operaciones de cirugía abdominal, cardiaca, torácica, pediátrica y ginecológica El brazo robotizado permite intervenir mediante laparoscopia mientras que desde la terminal de control el cirujano puede ordenar los movimientos; esto permite comunicar a distancia el brazo y la consola por lo que se puede emplear en operaciones donde la consola y el cirujano se encuentra en un lugar diferente de donde se realizaba la intervención. 
Ver link: www.bing.com/videos/search?q=Descripci\%c3\%b3n+del+Vinci+Xi+Robot\&\&view=detail\&mid=983CA28770C70F6BED67983CA28770C70F6BED67\&\&FORM $=$ VRDGAR

En este caso se presenta un trasplante preventivo de donante cadáver en el que el receptor era un varón de 37 años con hipertensión tratada, sin cirugía abdominal previa, con enfermedad renal terminal debida a una poliquistosis que aún no requería diálisis. El índice de masa corporal era de $21,9 \mathrm{~kg} / \mathrm{m}^{2}$, detectándose una masa asintomática palpable de flanco bilateral.

La ecografía confirmó la presencia de múltiples quistes significativamente aumentados de diferentes diámetros en los riñones. No se previeron restricciones de espacio en la fosa iliaca derecha por lo que no se indicó nefrectomía del riñón nativo.

El donante, con muerte cerebral, era un varón de 50 años, sin comorbilidades significativas, fallecido en un accidente automovilístico. En la tomografía computarizada, se observó una única arteria y vena renal. La técnica quirúrgica se realizó con éxito siguiendo los principios de la técnica Vattikuti-Medanta, previamente empleada para donantes vivos con modificaciones para adaptar la estrategia quirúrgica a la anatomía específica del paciente. La ecografía del injerto realizada en el día uno del postoperatorio mostró una perfusión del injerto normal y a los 6 meses de seguimiento la paciente estaba libre de síntomas, con función miccional regular, ausencia de linfocele en la ecografía abdominal y función renal óptima (eGFR 76,8 ml/min/ 1,73 m²)

Los autores destacan que el trasplante renal con robot puede ser realizado con seguridad por cirujanos robóticos con experiencia, incluso en trasplantes complejos, como ocurre con los pacientes poliquísticos y con donantes fallecidos.

\section{Deniz Demet, Nilgün Aksoy,Nihal Kiraz.Nursing Care After Kidney Transplant: Case Report Exp Clin Transplant. (2018) Supl 1:S55-60}

En este caso se revisan los aspectos fundamentales de la Enfermedad Renal y del Trasplante y su situación en Turquia en 2016 (933 pacientes por millón de población con Enfermedad renal y 3.416 trasplantes realizados). Se presenta el caso de una paciente que nació en 1993 y a la que a los 18 años se le diagnosticó una insufi- ciencia renal para la que se realizó tratamiento conservador durante cinco años. En 2016, dio a luz en un parto prematuro a las 32 semanas de embarazo debido a una preeclampsia, desarrollando una insuficiencia renal terminal que precisó diálisis urgente. La madre de la paciente se ofreció como donante y se procedió al protocolo de preparación para el trasplante que se realizó con éxito.

En el caso se describe el Plan de Cuidados que incluía los siguientes Diagnóstico Enfermero con su justificación y descripción de las intervenciones necesarias: Riesgo de sangrado, Dolor, Riesgo de compromiso respiratorio, Riesgo de infección, Riesgo de rechazo del injerto, Riesgo de desequilibrio de líquido y electrolitos todos ellos problemas comunes a todo paciente trasplantado. Debido a las circunstancias especiales de la paciente se formularon también los diagnósticos de Interrupción de la lactancia materna y Riesgo de deterioro de la vinculación entre padres y el lactante.

La educación sanitaria al alta incluyó a la paciente y a su familia con el fin de capacitarla para la adaptación al hogar y a su nueva situación Recibieron información sobre situaciones de emergencia, seguimiento clínico, tratamiento e interacciones medicamentosas, síntomas de rechazo o infección, cuidado de las heridas, medidas de higiene y protección del sol, manejo del dolor, nutrición, vida sexual, desplazamientos y ejercicio. En este caso se hizo énfasis en la educación para la lactancia y el cuidado del bebe.

Este artículo completo es asequible desde cualquier buscador y es recomendable su lectura porque, como los autores pretenden, contribuye al mejor conocimiento de las intervenciones enfermeras a un paciente trasplantado.

Recibido: 15 junio 2018

Revisado: 20 junio 2018

Modificado: 5 julio 2018

Aceptado: 10 julio 2018 


\section{Bibliografía}

1. Murray JE. Ronald Lee Herrick Memorial: June 15, 1931-December 27, 2010. Am J Transplant 2011;11(3):419

2. Julio Pascual, Ángel Alonso, Dolores Burgos, Josep M. Cruzado, Daniel Serón. Grupo Español de Consenso sobre Disfunción Renal Crónica en Pacientes Trasplantados Renales. Nefrología 2012;32(Supl 2):S1-28. doi: 10.3265/Nefrologia.pre2012. Mar. 11433

3. Vega, J. Cómo escribir y publicar un caso clínico. Guía práctica. Rev Med Chile 2015;143:499-05

Este artículo se distribuye bajo una Licencia Creative Commons Atribución-NoComercial 4.0 Internacional. https://creativecommons.org/licenses/by-nc/4.0/

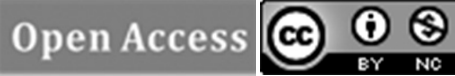

